\title{
Influence of serum on DNA protection ability and transfection efficiency of cationic lipid-based nanoparticles for gene delivery
}

\author{
Supusson Pengnam ${ }^{1}$, Lalita Leksantikul $^{1}$, Prasopchai Tonglairoum ${ }^{1}$, Praneet Opanasopit ${ }^{1}$, Nattisa Ni-yomtham $^{2}$, \\ Boon-Ek Yingyongnarongkul ${ }^{2}$, Samarwadee Plianwong, ${ }^{3 *}$ \\ ${ }^{1}$ Faculty of Pharmacy, Silpakorn University, Nakhon Pathom, 73000 Thailand \\ ${ }^{2}$ Department of Chemistry and Center of Excellence for Innovation in Chemistry, Faculty of Science, Ramkhamhaeng University, \\ Bangkok, 10240 Thailand \\ ${ }^{3}$ Faculty of Pharmacy, Burapha University, Chonburi, 20130 Thailand
}

\begin{abstract}
Cationic lipid-based nanoparticulate systems are delivery systems that has been widely used in pharmaceutical field including gene delivery. There are many barriers obstructing genetic materials and their delivery systems to reach the target. Serum is one of the imperative factor that should be investigated. Therefore, the aim of this study was to examine the effect of serum on DNA protection ability of spermineliposomes and niosomes by evaluating the percentage of transfection efficiency in Hela cell and observing the DNA degradation band using agarose gel electrophoresis in the presence of serum. The results showed that the percentage of transfection efficiency of spermine-liposomes was dramatically decreased when serum is presented $(p<0.05)$. In contrast, whether or not the serum is presented, the spermine-niosomes showed no significant difference in transfection efficiency. Concisely, liposomes could slightly protect DNA from DNase in the serum, whereas, niosomes had potential ability to protect DNA from the enzymes in serum. This result revealed an advantage of the cationic niosomes system as a gene carrier over the cationic liposomes.
\end{abstract}

\section{Introduction}

Numerous researches have been using cationic lipid-based nanoparticles (cLNPs) such as cationic liposomes and cationic niosomes for gene delivery which can be applied in various applications such as infectious diseases, metabolic diseases, cancers and regenerative medicines [1,3]. Liposomes are composed of cholesterol and non-toxic phospholipids which selfassembled as small artificial vesicles of spherical shape. Niosomes consist of non-ionic surfactant and cholesterol as excipients. Besides liposomes, niosomes show some significant advantages, such as low cost and storage stability [1]. Some literature indicates that genetic material has a short half-life in the blood circulation because of the rapid degradation caused by nucleases $[2,3]$. Otherwise cationic lipids are included in both carriers to generate positive charge in their systems and facilitate transfection by electrostatic interaction with DNA and cellular membrane. In the previous study, spermine-liposomes and niosomes exhibited a potential gene delivery and high transfection efficiency $[4,5]$. Generally, hypothesis of serum incompatibility with cLNPs begin through interaction between negative charge of serum proteins onto the positive charge of cationic systems affected electrostatic interaction with proteins on the cell surface and their internalization [8,9]. Therefore, the objective of this research is to explore the effect of serum on the DNA protection ability of liposomes and niosomes by evaluating the percentage of transfection efficiency in Hela cell and observing the DNA protection ability by agarose gel electrophoresis in the presence of serum.

\section{Materials and Methods}

\subsection{Materials}

Phosphatidylcholine (PC) (Phospholipon ${ }^{\circledR}$ 90G) was purchased from $\mathrm{GmbH}$, Nordrhein-Westfalen, Germany. Span20 (Sp20) were obtained from SigmaAldrich, MO. Cholesterol (Chol) and DOPE were purchased from Carlo Erba Reagenti, MI, Italy. Spermine-based cationic lipids (shown in Fig. 1) were synthesized via solid-phase synthesis in the previous

\footnotetext{
* Corresponding author: samarwadee.pl@go.buu.ac.th
} 
report [5]. HeLa cells; the human cervical cancer cell line was obtained from American Type Culture Collection (ATCC, Rockville, MD). The pEGFP-C2 plasmid DNA, encoding green fluorescent protein (GFP), was obtained from Clontech, CA. The Hind III were obtained from Promega, CA. Lipofectamine ${ }^{\circledR}$ 3000 was purchased from Invitrogen, NY. All other reagents were employed of cell culture and molecular biology quality.
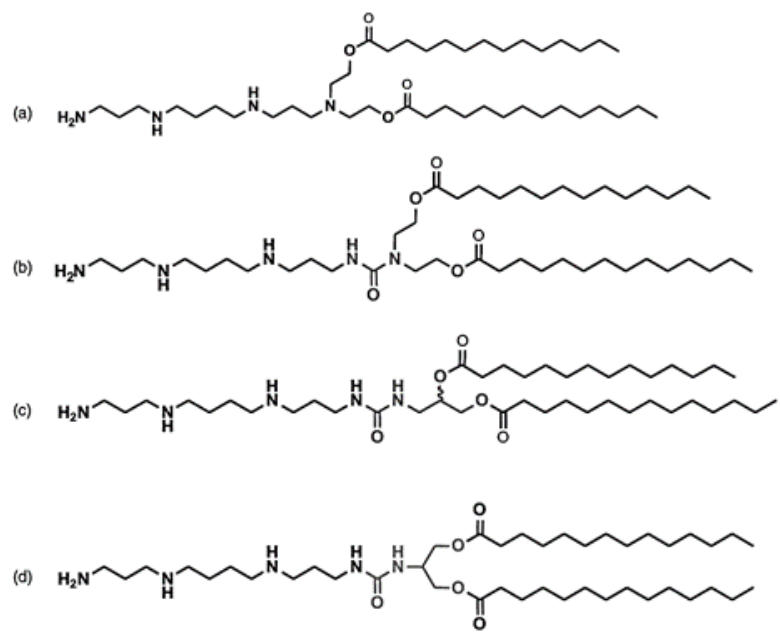

Fig. 1. different central core structures of the spermine-based cationic; di(oxyethyl)amino (a), di(oxyethyl)amino carboxy (b), 3-amino-1,2dioxypropyl (c) and 2-amino-1,3-dioxypropyl (d).

\subsection{Preparation of the cLNPs and the cLNPs/pDNA complexes}

The cLNPs were prepared using thin film hydration in ethanol:chloroform (1:1) with sonication method. This study performed 4 cationic lipids with different central core structure; di(oxyethyl)amino (a), di(oxyethyl)amino carboxy (b), 3-amino-1,2dioxypropyl (c) and 2-amino-1,3-dioxypropyl (d) that were showed in fig. 1 to prepared liposomes; $\mathrm{Li}-\mathrm{a}, \mathrm{Li}-$ b, Li-c, Li-d and niosomes; Ni-a, Ni-b, Ni-c, Ni-d, respectively. The optimal molar ratio of each formulation and the weight ratio of cLNPs to pDNA were obtained in the previous studies $[4,5]$. In brief, for cationic niosomes, the molar ratio of Sp20:Chol:cationic lipid was fixed at 2.5:2.5:0.5 mM. For cationic liposomes, the molar ratio of PC:DOPE:cationic lipid was fixed at 2.5:2.5:1.5 mM. Thin film was obtained after evaporated the solvent in a fume hood under $\mathrm{N}_{2}$ gas flow and left in a desiccator overnight. Then hydrated thin film with $\mathrm{pH}$ 7.4 Trisbuffer. After hydration, the particle size was reduced by bath sonicator for $30 \mathrm{~min}$ followed by a probe sonicator for $30 \mathrm{~min}$ with two cycles in ice bath. The prepared cationic niosomes were kept at $4{ }^{\circ} \mathrm{C}$.
Before the experimentations, pDNA and cLNPs were mixed to allow complexation, and incubated for $30 \mathrm{~min}$ at room temperature. The weight ratio of cLNPs to pDNA was fixed at 2.5:1 and 5:1 for niosomes and liposomes, respectively.

\subsection{Effect of serum on the transfection in HeLa cells}

HeLa cells were cultured in MEM with $10 \%$ FBS and cultured at $37{ }^{\circ} \mathrm{C}, 5 \% \mathrm{CO}_{2}$ for $24 \mathrm{~h}$ in 48 -well plate by seeding density of $1 \times 10^{4}$ cells/well. The cLNPs/pDNA complexes were separated into 2 groups that were diluted with two different transfection mediums. One was diluted with MEM with $10 \%$ FBS, the other was diluted with serum-free MEM. After 6 $\mathrm{h}$, the medium was replaced with MEM with $10 \%$ FBS and the cells were incubated at $37{ }^{\circ} \mathrm{C}$ under $5 \%$ $\mathrm{CO}_{2}$ for $48 \mathrm{~h}$. The transfected cell (TF) was observed under fluorescence microscopy and calculated in term of percentage of transfection efficiency according to equation 1. Naked pDNA and Lipofectamine ${ }^{\circledR}$ $3000 /$ pDNA complexes were incubated as a negative control and a positive control, respectively.

$$
\underset{\begin{array}{c}
\text { transfection } \\
\text { efficiency }
\end{array}}{\%}=\frac{[\mathrm{TF}(\mathrm{cLNPs})-\mathrm{TF} \text { (negative) }) \times 100}{\left[\mathrm{TF} \text { (positive) }-\mathrm{TF}_{\text {(negative })}\right]}
$$

\subsection{Serum stability of pDNA in the cLNPs/pDNA complexes}

The cLNPs/pDNA complexes with the optimal weight ratio was incubated with serum at $37^{\circ} \mathrm{C}$ for $6 \mathrm{~h}$. Then, heated at $70{ }^{\circ} \mathrm{C}$ for $15 \mathrm{~min}$ to inactivate the serum enzymes. After that, $0.5 \%$ sodium dodecyl sulfate (SDS) solution was added to the sample to extract pDNA from the cLNPs and further incubated at room temperature for $10 \mathrm{~min}$. The extracted pDNA was analyzed using $1 \%$ agarose gel electrophoresis for $45 \mathrm{~min}$ at $100 \mathrm{~V}$. The DNA bands were visualized under a UV transilluminator using a GelDoc system. A naked pDNA was tested under the same conditions as control.

\subsection{Statistical analysis}

All experiments were performed in triplicate measurements and the data was represent as mean \pm standard deviation (SD). Statistical analysis of the data was examined by F-test and t-test (Microsoft ${ }^{\circledR}$ Excel ${ }^{\circledR}$ 2016 MSO for Windows) with $p<0.05$.

\section{Results and discussion}


The optimal formula of the niosomes and liposomes in the previous studied were selected to compare the effect of serum on the transfection ability between liposomes and niosomes [4, 5]. All experiments were tested along with lipofectamine ${ }^{\circledR}$ 3000 to obtain a percentage of transfection efficiency. From the results in Fig. 2, serum affected to the transfection efficiency of all liposome formulations. Although Li-d showed high transfection (104.17\%), the percentage of transfection efficiency was dramatically decreased to $59.49 \%$ with the presence of serum $(p<0.05)$. In contrast, when the cationic lipids were prepared as niosomes, no significant effect of serum on the percentage of transfection efficiency has been observed ( $p>0.05)$.

The DNA protection ability was investigated by gel agarose electrophoresis after complexing with cLNPs. DNA band could not be observed when pDNA was contacted with serum (positive control, lane 3 in Fig. 3a, 3b). The percentage of transfection efficiency of spermine-liposomes in the presence of serum was displayed in Fig. 3a (lane 4-8). DNA bands of the complexes was faded compared with the DNA band which was not contacted with serum (lane 4 , negative control), indicating that DNA degradation may occur in the presence of serum. However, the DNA bands were not clearly disappeared. Therefore, liposome formulations may slightly protect DNA from degradation. On the other hand, the niosome formulations exhibited ability to protect DNA for at least $6 \mathrm{~h}$ as it can be seen from the DNA bands (Fig. $3 \mathrm{~b}$; lane 4-8). This result was consistent with the transfection efficiency result. However, niosomes which are composed of non-ionic surfactants might be more stable than liposome formulation which consisted of phospholipids. The phospholipids contained in liposomes may be subjected to oxidation and degradation by phospholipases in the blood circulation [6, 7]. Therefore, liposomes might be degraded by serum before internalization. Serum is a one important factor that should be considered to break through the delivery barrier.

The effect of different central core structure of cationic lipids to transfection efficiency was reported in the previous study $[4,5]$. In addition, the effect of different central core structure of cationic lipids with or without urea functional group on DNA protection ability in presence of serum was showed in fig. $3 \mathrm{~b}$. Niosomes with cationic lipid a exhibited high intensity of released DNA band. Notice that cationic lipid a without urea in their structure provides slightly higher DNA protection ability than the other cationic lipids with urea $(b, c, d)$. The intensity of released
DNA band from liposomes in fig. 3a did not show the difference of intensity in each cationic lipid. The stability of phospholipid in serum that contained in liposomes might affect DNA protection ability more than the effect of central core structure. However, structure-activity relationships of changing central core structure was enigmatical [10].

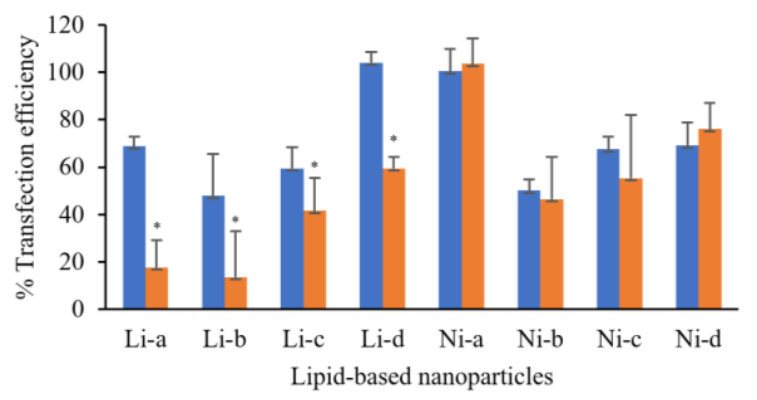

Fig. 2. Percentage of transfection efficiency of spermine-liposomes (Li-a, Li-b, Li-c, Li-d), and spermine-niosomes (Ni-a, Ni-b, Ni-c, Ni-d) (ロ) without serum and $(\square)$ with serum. Data was represented as mean \pm standard deviation in triplicate measurements. 'Significant different from without serum $(p<0.05)$

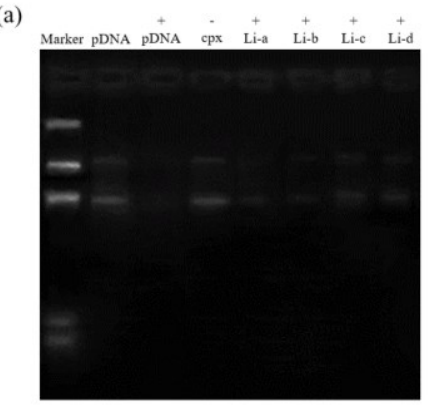

)

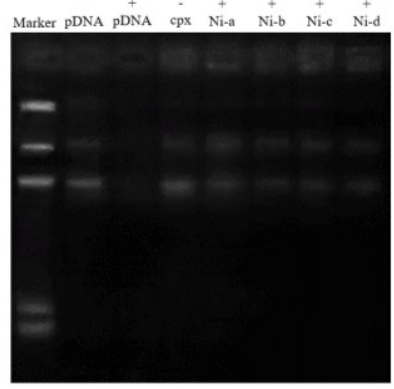

Fig. 3. Agarose gel images of (a) liposome formulations and (b) niosome formulations under the $(+)$ presence of serum for $6 \mathrm{~h}$ and $(-)$ absence of serum.

\section{Conclusion}

Serum contains various enzymes that may affect the transfection efficiency and DNA protection ability of a gene delivery system. In order to improve the transfection efficiency, the delivery systems need to have the ability to protect the DNA from being destroyed by DNase in the serum. From this study, spermine-liposomes could slightly protect the DNA from DNase in the serum. On the other hand, spermine-niosomes exhibited potential ability to protect the DNA whether or not the serum was presented. Therefore, this is the another strength of a cationic niosomes as gene carrier over cationic liposomes. Otherwise spermine-based cationic lipid 
with no urea provides slightly higher DNA protection ability than cationic lipids with urea in central core structure. However, structure-activity relationships of changing central core structure was enigmatical. It was necessary for study new compounds containing different central core structures, which might be useful for the development of cationic lipid-based gene delivery.

\section{References}

1. K.M. Kazi, A.S. Mandal, N. Biswas, A. Guha, S. Chatterjee, M. Behera, K. Kuotsu, J Adv Pharm Technol Res. 1(4), 374-380 (2010)

2. M. Saffari, H.R. Moghimi, C.R. Dassc, Iran J Pharm Res. 15(Suppl), 3-17 (2016)

3. X. Cheng, R.J. Lee. Adv. Drug Deliv. Rev. 99, 129137 (2016)

4. O. Paecharoenchai, N. Niyomtham, L. Leksantikul, et al. AAPS PharmSciTech. 15(3), 722-30 (2014)

5. Niyomtham $\mathrm{N}$, Apiratikul $\mathrm{N}$, Suksen $\mathrm{K}$, et al. Bioorg Med Chem Lett. 25, 496-503 (2015)

6. M.N. Jones, A.R. Nicholas. Biochim Biophys Acta. 1065(2), 145-52 (1991)

7. K. Agarwal, A. Bali, C.M. Gupta. Biochim Biophys Acta. 856(1), 36-40 (1986)

8. T. Sato, T. Ishii, Y. Okahata. Biomaterials. 22(15), 2075-80 (2001)

9. S. Li, W.C. Tseng, D.B. Stolz, et al. Gene Ther. 6(4), 585-94 (1999)

10. D. Zhi, Y. chao, B.J. Yang, et al. Adv. Colloid Interface Sci. 253, 117-40 (2018) 